\title{
Gas Desorption and Transportation in Original Coal of Baijiao Coal Mine Under Temerature-stress Loading Condition
}

\author{
X.H. Zhang ${ }^{1,2, a^{*}, Y . \text { Chang }^{1,2, b} \text { and X.L. Ren }}{ }^{1,2, c}$ \\ ${ }^{1}$ School of Mechanics, Architecture and Civil Engineering, China University of Mining and \\ Technology, Beijing, China \\ ${ }^{2}$ State key laboratory for Rock mechanics and Deep underground Engineering, Beijing, China \\ azhangxiaohucumtb@163.com, bchangyuancumtb@163.com, ccumtbdragon@163.com
}

Keywords: desorption; transportation; concentration; gas emition; crack volumetric strain;

\begin{abstract}
This paper presents experimental investigation on gas desorption and transportation in bulk coal under temperature-stress conditions, focusing on gas emition at three stages, heating stage, uniaxial loading stage and confined pressure loading stage. These tests conducted to simulate the effects of underground mining conditions on bulk coal itself were carried out by a Coal Sample Temperature-Pressure Coupling Experimental System. Through these tests, the desorptive volume of sampled gases were measured, the relationship between crack propagation and gas emit pressure was studied, the emitted gas volume and sampled gases' concentrations of each stage were compared. The results show that $\mathrm{CH} 4$ has a larger desorption rate than $\mathrm{CO} 2$, confined pressure contributes more to gas emition than the uniaxial stress, and it will result in high gas pressure and high concentration of sampled gases, which will cause high possibility of danger.
\end{abstract}

\section{Introduction}

A large amount of gases especially methane are formed during the stage of coalification, and are subsequently stored in coal. And the release of coalbed methane (CBM) in coal mining operations has always been a serious problem such as coal and gas outbursts. Coal is a typical dual porosity system in nature which contains porous matrix surrounded by fractures [1]. And the internal surface area where the CBM is adsorbed is very large [2]. All these pores and surfaces are the main lebensraum of CBM. CBM is primarily stored in such spaces in coal in adsorbed form due to the extremely large area of internal surface.

Temperature programed desorption was defined and refined by many authors they treat desorption as a reaction and an endothermic stage which follows the Arrhenius equation, and higher temperature with higher desorption rate. The adsorption energy of $\mathrm{CO} 2$ is higher than $\mathrm{CH} 4$, this means $\mathrm{CH} 4$ will has a higher desorption rate in the same conditions [3] which was used to increase the recovery of $\mathrm{CH} 4$. The previous works mostly focus on the molded coal, which could not represent the true fractural and porous properties. In the present work, the raw coal from Baijiao Coalmine of China was selected to investigate the effects of temperature, axial stress and confined pressure on desorption and emition of the original adsorptive gas in coal. These tests include three stages, heating stage, uniaxial loading stage and confined pressure loading stage. The relationship between gas emition and crack behavior was studied during the uniaxial loading stage and the confined pressure loading stage. Meanwhile, all the detected parameters were plotted and compared to make a through inquiry of the differences of each stage.

\section{Experiment}

The coal block, approximately $400 \times 350 \times 300 \mathrm{~mm}$, was gained from NO2442 working face at the depth of $-980.02 \mathrm{~m} \sim-982.13 \mathrm{~m}$ of Baijiao coal mine which is located in Furong mining district in Sichuan province. It was immediately sealed with several valve bags. And after that the block was directly transported to the laboratory the next day. And then we drilled out 5 cylindrical specimens which were $\Phi 50( \pm 1) \mathrm{mm} \times 100( \pm 1) \mathrm{mm}$ in size. Both the specimens were sealed with valve bags immediately preventing to be shined or oxygenized. The coal is classified as lower rank coal 
estimated as anthracite with high ash and high sulphur. The Furong coal mine is famous for its enrichment of methane gas. And at the depth of $1000 \mathrm{~m}$, the temperature can reach $40^{\circ} \mathrm{C}$, combined with the increasing mining stress, the coal mass with low strength then has a high risk of gas burst.

The experiments were carried out by a system called Coal Sample Temperature-Pressure Coupling Experimental System in State Key Laboratory for Geomechanics and Deep underground Engineering, Beijing, China. The radial deformation was measured by a circumferential extensometer which has four claws fixed in the surface the coal sample, and the gap between the claws and the rubber sleeve is sealed by silicon gel, so that the gas won't escape through the gasp. The axial deformation was measured by an axial strain jig with two plates at each end and four arms, and these plates were fixed to the blocks located at the end of the sample. All this deformation information is recorded by computer. The volumetric strain is calculated from the following equation,

$$
\varepsilon_{v}=\varepsilon_{a}+2 \varepsilon_{r}
$$

Where $\varepsilon_{\mathrm{a}}$ and $\varepsilon_{\mathrm{r}}$ are the axial and lateral strains, respectively. Meanwhile the crack volumetric strain $\varepsilon_{\mathrm{v}}$ is defined by [4],

$$
\varepsilon_{c v}=\varepsilon_{v}-\frac{1-2 v}{E} \sigma_{a}
$$

Where $\sigma_{\mathrm{a}}$ is the axial stress, $\mathrm{E}$ is the Young's modulus, and $\mathrm{v}$ is the Poisson's ratio.

The heating unit includes a heating controller and two temperature transmitters. The heating controller controlled the temperature of oil and temperature transmitter. Another temperature transmitter was adhered to the coal surface is connected to a small displayer and also were recorded. The gas flowed out through a channel, $2 \mathrm{~mm}$ for the inner diameter, in the upper piston. And this channel was connected to the measurement- monitoring unit which consist of a high-resolution gas pressure transducer ( full scale $\pm 1000 \mathrm{~Pa}$, with a precision of $0.1 \%$ ) by HELM Corporation of Germany and two different scale gas flowmeters (one for $0 \sim 5 \mathrm{ml} / \mathrm{min}$, the other for $0 \sim 50 \mathrm{ml} / \mathrm{min}$ ) by AALBORG Corporation of USA. And we choose them by the amount of the gas flux. We use a Gas Chromatography (GC) equipped with a Thermal Conductivity Detector (TCD) and a Flame Ionization Detector (FID) to detect each kind of gas (mainly hydrocarbon and carbon dioxide) and its concentration. All the data such as gas pressure, flux and each gas's concentration were recognized in Computer 2. In order to obtain a relatively accurate result, the GC is calibrated repeatedly by the Universal Gas Calibration Stan before test.

This test focus on desorption of the original adsorptive gas in stressed coal matrix under isothermal condition, so we consider two aspects, temperature and stress. Take sample 1\# for example, the testing procedure is simply expressed by the following steps,

1) Increase the temperature from $25^{\circ} \mathrm{C}(298 \mathrm{~K})$ to $40^{\circ} \mathrm{C}(313 \mathrm{~K})$ at the rate of $0.5^{\circ} \mathrm{C} / \mathrm{min}$ and then retain the temperature at $40^{\circ} \mathrm{C}$.

2) Do the uniaxial test with no confined pressure.

3) Increase up the confined pressure to the stepwise of 3, 6 and $9 \mathrm{MPa}$ at the rate of $0.05 \mathrm{MPa} / \mathrm{s}$. In such manner, we study the desorption difference from step 3) During 2), 3) and 4), the releasing gases were sampled and detected by GC.

\section{Results and discussion}

It took 100 min to attain these isothermal conditions evaluated from $25^{\circ} \mathrm{C}$ for sample $1 \#$. As were shown in Fig. 2 and 3, three main stages: I for heating stage, II for uniaxial loading stage and III for confined pressure loading stage were especially marked. (a) shows the real time changes of stress, temperature and the cumulative volume of gas. (b) shows the real time changes of gas pressure and sampled gases' concentrations.

3.1 Heating stage 
As were presented in Fig. 1, we found the sampled gas volume of $\mathrm{CH} 4$ for sample $1 \#$ is 0.27 $\mathrm{ml}, \mathrm{CO} 2$ is and $0.009 \mathrm{ml}$ and $\mathrm{C} 2 \mathrm{H} 6$ is $0.00025 \mathrm{ml}$. The sampled volume of gas increased when temperature evaluated, and higher temperature correspond to higher desorption values, which means the adsorptive capacity of coal is decreased (M.C HE 2010).

The concentrations of the sampled gases are also increasing along with the temperature. The total values of the sampled gases' concentration for sample1\# are $5.97 \%$ for $\mathrm{CH} 4,0.64 \%$ for $\mathrm{CO} 2$ and $0.0055 \%$ for $\mathrm{C} 2 \mathrm{H} 6$. We find that $\mathrm{CH} 4$ has a larger concentration than $\mathrm{CO} 2$ or $\mathrm{C} 2 \mathrm{H} 6$, and the major components of coal gas is $\mathrm{CH} 4$, the desorption rate of $\mathrm{CH} 4$ is $0.004046 \mathrm{ml} / \mathrm{min}$ and that of $\mathrm{C} 2 \mathrm{H} 6$ is $0.000495 \mathrm{ml} / \mathrm{min}$ for sample 1\#. Another phenomenon is that gas pressure seems more complex than the other parameters, but still we found that more positive gas pressure occurs during the faster changing of temperature.

3.2 Uniaxial loading stage

Part (II) derived in Fig. 1 shows the information during the uniaxial test. The failure of brittle material can be divided into five regions [5] . $\sigma_{\mathrm{cc}}$ is the crack closure stress level, $\sigma_{\mathrm{ci}}$ is the crack initiation stress level, and $\sigma_{\mathrm{cd}}$ is the crack propagation stress level, and the $\sigma_{\mathrm{f}}$ is the peak stress level. Sample 1\# was chosen as an example to analyze the crack propagation process. The crack parameters for sample1\# were calculated by Eq. 2 as follows,

$$
\sigma_{c c}=0.22 \sigma_{f} \quad \sigma_{c i}=0.43 \sigma_{f} \quad \sigma_{c d}=0.78 \sigma_{f}
$$

Region I is the region where the initial inner cracks close with the increase of uniaxial stress, as can be seen in Fig 2 . The calculated crack volumetric strain decreases from $-0.15 \%$ to 0 , and the gases pressed in the interconnected pores and fracture are squeezed by the axial pressure during this region, no new cracks are produced, and positive gas pressure values take a larger part of this region. Region II is the elastic region. In this region, the strain is only the elastic strain of the coal matrix, the calculated crack volumetric strain is 0 , no crack produced and accordingly the gas pressure has no stark changes.

Region III is the stable crack growth region. The calculated crack volumetric strain increases from 0 to $-0.07 \%$, and it is obvious to find out two major lager negative gas pressure values, $-20.88 \mathrm{~Pa}$ at $195.7 \mathrm{~min}$ and $-13.13 \mathrm{~Pa}$ at $196.7 \mathrm{~min}$. These larger negative represent the sudden growth of $\varepsilon_{\mathrm{cv}}$, we regard them as tensile cracks. $\sigma_{\mathrm{cd}}$ is also where the largest volume strain happens.

Region IV from is the unstable crack growth region. It can be seen in Fig 2 that more and more larger negative gas pressure values occur, which means more and more tensile cracks are formed. The calculated crack volume strain increases from $-0.07 \%$ to $-3.5 \%$. When the sample fails at $\sigma_{\mathrm{f}}$, the fracture and pores interconnect together which forms a largest volume with low pressure, as a result, the largest negative value $-88.5 \mathrm{~Pa}$ at 202.4 min turns up. The concentration of each sampled gas $\mathrm{CH} 4$ reduces to $3.85 \%, \mathrm{CO} 2$ to $0.49 \%$ and $\mathrm{C} 2 \mathrm{H} 6$ to $0.0035 \%$. The coal sample will recover elastically a 
little after the failing point $\sigma$, and along with the closure of some cracks, larger positive gas pressure value $65.5 \mathrm{~Pa}$ at $206.4 \mathrm{~min}$ occurs. There are $0.146 \mathrm{ml}$ gases emitted from the coal sample 1 \# during the uniaxial stages.

\subsection{Confined pressure loading stage}

Fig. 3 shows the confined pressure loading stages for sample 1\#. The pressure level is $4 \sim 10 \mathrm{MPa}$ which has been tested in-situ underground. As is shown in Fig. 3, the pressure levels were $6 \mathrm{MPa}$ for sample 1\#. Since all these samples tested have failed, the confined pressure plays a role of compressing the volume of pores and fracture, which consequently reduces the passageway of the original compressed gases, and squeezes them out through these passageways. And larger positive gas pressure occurs at each pressure level, taking sample 1\# for example there are three major larger positive intervals,

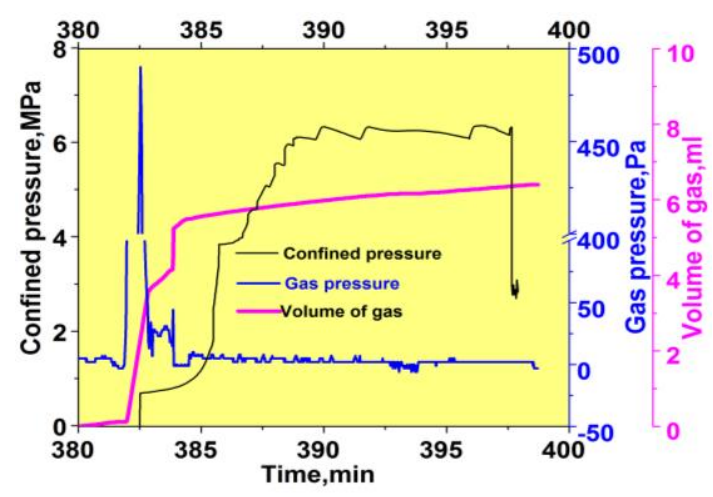

Fig 3 Confined pressure loading process of sample $1 \#$ about $382 \mathrm{~min}$ at $6 \mathrm{MPa}$. There is only one larger positive interval for sample 1\# in Fig. 3 at the beginning of the loading, because we increased the pressure to $6 \mathrm{MPa}$ directly. The total emitted gas volumes during this stage is $6.62 \mathrm{ml}$, and the concentration for the sampled $\mathrm{CH} 4$ rises up from $4.3 \%$ to $12.5 \%$, which can be derived in Fig. 1.

\section{Summary}

Desorption and transportation of original adsorptive coal gas have received increasing interest in the world. It deals with complex gas desorption, diffusion and flow in bulk coals. To improve understanding of such process, three tests were conducted under controllable isothermal conditions. There are three major stages for each test, heating stage, uniaxial loading stage and confined pressure loading stage. Higher temperature corresponds to higher emitted volume of gas, and will lead to higher dangerous concentration of sampled gases, such as Sample1\#. And CH4 has a larger desorption rate than $\mathrm{CO} 2$ and it is different for different samples. There is little gas emitted during the uniaxial stage, and the sampled gases' concentration decreases. Gas pressure has a very close relationship with crack propagation, larger positive values mean crack coalescence and higher permeability, and larger negative values mean tensile crack propagation. Confined pressure attributes much more to the gas volume, and will result in higher sampled concentration.

\section{References}

[1] Lu, M., Connell, L.D. A model for the flow of gas mixtures in adsorption dominated dual porosity reservoirs incorporating multi-component matrix diffusion: part I. Theoretical development. Journal of Petroleum Science and Engineering, (2007), 59 (1-2), 17-26.

[2] Patching, T.H. Retention and release of gas in coal - a review. Canadian Mining and Metallurgical Bulletin 63 (1970), 1302-1308.

[3] M.C. He , C.G. Wang, J.L. Feng et al. 2010. Experimental investigations on gas desorption and transport in stressed coal under isothermal conditions, International Journal of Coal Geology 83(2010), 377-386.

[4] Martin CD. The strength of massive Lac du Bonnet granite around underground opening. Ph.D. thesis, p278, (1993).

[5] Cai, M. Influence of intermediate principal stress on rock fracturing and strength near excavation boundaries-Insight from numerical modeling. International Journal of Rock Mechanics and Mining Sciences 45(2008), 763-772. 